\title{
EEN IEPERS GEVANGENISREGLEMENT MET DE RECHTEN VAN DE CIPIER, CA. 1500'
}

\author{
R. OPSOMMER ${ }^{\circ}$
}

Onlangs vonden we in het Algemeen Rijksarchief een tekst terug die het reglement van de Ieperse gevangenis weergeeft, zoals het in de eerste helft van de 16de eeuw in zwang was ${ }^{2}$. De tekst is neergeschreven op een zwaar beschadigd blad perkament dat gehecht is aan een suppliek die de Ieperse burggravin, Claudine Hugonnet, gezegd de Saillant, dame van Middelburg, anno 1551 aan de Rijselse Rekenkamer richtte. Het burggraafschap van Ieper, een leen van het grafelijk leenhof "de Zaale", omvatte o.a. de gevangenis van Ieper $^{3}$. In de suppliek vroeg de leenhoudster ondermeer dat de vorstelijke baljuw van Ieper het gevangenisreglement zou onderhouden, en de hieruit voortvloeiende (financiële) verplichtingen zou naleven. Daartoe heeft de burggravin het reglement laten kopiëren.

Uit welke periode het reglement precies dateert, valt niet meer te

- Faculteit Rechtsgeleerdheid, KULCK, Universitaire Campus, 8500 Kortrijk.

1. We bedanken prof. dr. J. Monballyu voor zijn kritische hulp bij de realisatie van dit artikel.

Afkortingen : d. $=$ denier $; \operatorname{Pr}$. civ. $=$ Practijcke civile $; \operatorname{Pr}$. cri. $=$ Practijcke criminele $; \mathrm{s} .=$ schelling.

2. BRUSSEL, ALGEMEEN RIJKSARCHIEF, Cartons Rekenkamer, 1ste reeks, 228. Zie bijlage.

3. De grootvader van Claudine had het leen in 1474 gekocht. Door het huwelijk van Claudine met Martin de Hames zou het burggraafschap naar laatstgenoemde familie overgaan. Coutumes des pays et comté de Flandre. Quartier d'Ypres. Coutume de la salle et châtellenie d'Ypres, uitg. L. GILLIODTS-VAN SEVEREN, (Recueil des anciennes coutumes de la Belgique), Brussel, 1911, p. XXV ; J.-L. DE JOIGNY, Manuscrit relatif aux Seigneuries de Flandre, uitg. H. DE LIMBURG-STIRUM, Oudenaarde, 1935, p. 11-12. 
achterhalen. Daar er sprake is van de braspenning, een onder Karel de Stoute ingevoerde munt, kunnen we de terminus ante quem op ca. 1470 plaatsen ${ }^{4}$. Het reglement bevat heel wat elementen waarvan ook sprake is in de bekende werken van de rechtsgeleerde Filips Wielant: "Corte instructie omme jonghe practisienen in materie criminele", gewoonlijk "Practijcke criminele" genoemd (1508-1510) en "Corte instructie omme jonghe practisienen in materie civile", beter bekend onder de benaming "Practijcke civile" (1519) . De inhoud vertoont eveneens enkele gelijkenissen met titel IL van de uit 1535 daterende stedelijke ontwerpcostumen (Cahier primitif, IL : Van den ghevanghenen persoonen ende cipaige $)^{6}$. Toch ligt de klemtoon van het hier weergegeven reglement op het pecuniaire aspect : vooral de ontvangsten van de cipier en de regeling der teerkosten komen aan bod, terwijl de ontwerpcostumen de nadruk legden op de interne gevangeniswerking en orde : hoe worden gevangenen opgesloten, onder welke omstandigheden kan men vrijgelaten worden... Uit dit alles menen we te mogen opmaken dat het reglement zoals het hier voorligt uit de late $15 \mathrm{de}$ of vroege $16 \mathrm{de}$ eeuw dateert.

Waar de Ieperse gevangenis precies gelegen was, weten we niet. Ongetwijfeld niet ver van de Markt en de Hallen. De gevangenis vormde een apart gebouw, en was voor een deel ondergronds aangelegd. In artikel 11 heet het immers dat men de gevangenen bovenaan, binnen de afgesloten ruimte van de gevangenis moest afleveren ("boven binder duere ende pourprijse").

De vergoedingen welke cipiers opstreken waren in Vlaanderen

4. 1 braspenning $=1$ dubbel stuiver $=4 \mathrm{~s}$. par. K. STALLAERT, Glossarium van verouderde rechtstermen..., dl.I, Leiden, 1890, p.281 ; P. VANDEWALLE, Oude maten, gewichten en muntstelsels in Vlaanderen, Brabant en Limburg, Gent, 1984, p. 65-66.

5. Het handelt hier om enkele juridische onderwerpen die bij de eminente jurist Wielant in zijn beide standaardwerken ter sprake komen. Het lijkt ons nuttig om verder te verwijzen naar de artikels uit de gedrukte versies van zowel de Practijcke civile, Antwerpen, 1573, anastatische herdruk, uitg. E. STRUBBE, Amsterdam, 1968, (Fontes iuris Batavi rariores, nr. 3) ; P. WIELANT, Practijcke criminele, uitg. A. ORTS, Gent, 1872.

6. De auteur van de ontwerpcostumen ontleende niet letterlijk aan het hier weergegeven reglement. Wel kan je stellen dat de artikels $1,2,3,5$, 6 en 7 van titel IL inhoudelijk hetzelfde thema behandelen als artikel 15 van dit reglement. Coutume de la ville d'Ypres, uitg. L. GILLIODTS-VAN SEVEREN, (Recueil des anciennes coutumes de la Belgique), dl.I, Brussel, 1908, p.462-467. 
geregeld volgens de hertogelijke ordonnantie van 23 mei $1401^{7}$. Het eerste artikel van die ordonnantie bepaalde dat behoeftige gevangenen op kosten van de vorst in de gevangenis verbleven. Daarvoor was een vergoeding van $3 \mathrm{~s}$. $6 \mathrm{~d}$. par. voorzien : $2 \mathrm{~s}$. diende voor voeding (pain, potage et servoise) terwijl de resterende $1 \mathrm{~s} .6 \mathrm{~d}$. het boeigeld (ysergheld) "pour le cepage, le lit et les appartenances" was. Het tweede artikel gaf aan dat gevangenen die wel over voldoende geld beschikten dagelijks $6 \mathrm{~s}$. par. moesten betalen : $2 \mathrm{~s}$. als boeigeld en $4 \mathrm{~s}$. voor voeding. In ruil voor deze laatste som moest men hen dan wel voorzien van brood, soep, licht, vlees. Dit laatste product werd op bepaalde dagen waarop de kerk het derven van vlees voorschreef vervangen door haring. Eventueel konden de gevangenen wijn bekomen, maar dan moesten ze wel nog eens $2 \mathrm{~s}$. par. extra afdokken. De maximale dagelijkse logiesprijs bedroeg dus $8 \mathrm{~s}$. par. De regeling van 1401 werd trouwens door Wielant getrouw overgenomen (Pr. civ., 9-XXXIX-2).

In het Ieperse reglement vormen de ontvangsten waarop de cipier recht had de cruciale gegevens. Zo geven de eerste acht artikels aan op welke vergoedingen de cipier recht had al naargelang de aard van de gevangenname : boeigeld, teerkosten en in bepaalde gevallen extra-vergoedingen. De artikels 12 en 13 omschrijven nader het begrip teerkosten. Ook de overige artikels staan direct of indirect in verband met de kosten van de cipier.

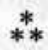

Laat ons nu eerst eens nagaan waarop de cipier recht had al naargelang de aard van de gevangenname. In vier gevallen had de Ieperse cipier recht op een vast boeigeld van één braspenning per dag, teerkosten (4 à $6 \mathrm{~s}$. par. per dag) en $28 \mathrm{~s}$. par. van "uut ende ingane" (artikels 1, 2, 4, en 5). De braspenning of dubbele stuiver vertegenwoordigde een waarde van $4 \mathrm{~s}$. par. ${ }^{8}$. Dit betekende dat de regeling van 1401 rond 1500 voor wat de teerkosten aangaat nog ongewijzigd werd toegepast, terwijl het boeigeld verdubbeld was.

7. Ordonnances de Philippe le Hardi, de Marguerite de Male et de Jean sans Peur, dl. II : Ordonnances de Philippe le Hardi et de Marguerite de Male, uitg. A. VAN NIEUWENHUYSEN, (Receuil des ordonnances des Pays-Bas, reeks I : 1381-1506), Brussel, 1974, p. 478-480.

8. Zie voetnoot 4 . 
Waarom het tarief voor de teerkosten niet, en deze voor het boeigeld wel aangepast was, weten we niet. Merk bij dit alles nog op dat de zilvermunten uit de periode rond 1500 een veel lager zilvergehalte hadden dan deze welke in 1401 in omloop waren'.

Dit vergoedingssysteem, inclusief de extra $28 \mathrm{~s}$., was vooreerst van toepassing bij personen die op vraag van een schuldeiser gevangengezet waren. Het betreft hier dus een vorm van gijzeling of bewarend beslag op een persoon. De bedoeling van de schuldeiser was ervoor te zorgen dat de schuldenaar zich niet zou verwijderen en als dusdanig nooit zijn schulden zou vereffenen. Volgens Wielant moest de persoon die om de gevangenneming verzocht had voor de onkosten instaan (Pr. civ. 2-XII-14) (artikel 1).

De cipier kreeg volgens artikel 2 dezelfde vergoedingen bij lieden die in de gevangenis waren beland, nadat ze door de baljuw vervolgd waren, een compositie (een soort minnelijke schikking) of een boete hadden opgelopen, en dan deze boete of compositie niet hadden betaald ${ }^{10}$. Het betreft hier een vorm van bewarend beslag op een persoon, waarbij men de persoon zolang vasthield tot hij de compositie of boete vereffende (Pr. cri., XVI, p. 22-23).

Dezelfde modaliteiten golden voor personen, die na een klacht door een partij en waarbij de partij hun arrestatie had gevraagd, door de baljuw gearresteerd waren. Ook in een dergelijke burgerlijke strafzaak moest de klagende partij voor de onkosten instaan (Pr. cri., XVII, p. 26-27) (artikel 4).

Ten slotte bepaalde artikel 5 dat dit gewone stelsel van toepassing was bij gevangenen die door de baljuw strafrechtelijk vervolgd werden ("ter cause van crime"), maar waarbij de baljuw in de loop van de tijd zijn criminele vordering had omgezet in een civiele vordering. Dit omzetten tot een burgerlijke strafzaak kwam trouwens vrij vaak voor (Pr. cri., XXIX, p. 46) ${ }^{11}$.

9. Een goede inleiding over het XVde-eeuwse muntwezen biedt J. VAN HOUTTE, R. VAN UYTVEN, Financien, -NAGN, dl. IV, Haarlem, 1980, p. 118-121.

10. Voor het compositierecht raadplege men J. VAN ROMPAEY, Het compositierecht in Vlaanderen van de veertiende tot de achttiende eeuw, - Tijdschrift voor Rechtsgeschiedenis, dl. XXIX, 1961, p. 43-79.

11. J. MONBALLYU, De bestraffing van weerspannigheid door de Raad van Vlaanderen in het begin van de 16e eeuw. Het proces Roeland Duernaghele, 1511-1513, - Recht en Instellingen van de Oude Nederlanden tijdens de Middeleeuwen en de Nieuwe Tijd.-Liber Amicorum Jan Buntinx, (Symbolae Facultatis Litterarum et Philosophiae, reeks A, nr. 10), Leuven, 1981, p. 357. 
In een aantal gevallen had de cipier alleen recht op boeigeld en teerkosten. Dit was vooreerst het geval bij personen die een gevangenisstraf hadden opgelopen. De gevangenisstraf was in die tijd eerder uitzonderlijk, maar Wielant geeft aan dat ze wel degelijk voorkwam : “... es den weerlicke juge wel ghecostumeert te pijnen of punieren met vanghenesse..." (Pr. cri., XVI, p. 22) (artikel 6).

Eenzelfde vergoedingssysteem gold krachtens artikel 7 voor de bewaring van lieden die nadat ze gedaagd waren (al dan niet op verzoek van een partij) zichzelf in de gevangenis plaatsten om zodoende op gelijke voet te staan als de tegenpartij bij de aanvang van het proces. Het was eveneens van toepassing bij personen die een purgeprocedure ingesteld hadden. De purge was een juridische procedure waarbij iemand zich voor een rechtbank van een beschuldiging of verdenking liet zuiveren. Bij zo'n purge was het de gewoonte dat men zich vrijwillig gevangen gaf (Pr. cri., XLIV, p. 67-68).

De derde mogelijkheid deed zich voor wanneer de baljuw iemand had vervolgd wegens een misdrijf waarop een boete stond. Had hij de persoon gearresteerd, en werd de beklaagde na die voorlopige aanhouding door de rechtbank vrijgesproken, dan mocht de cipier enkel teerkosten aanrekenen (artikel 3).

Een speciale regeling, voorzien in artikel 8, gold voor personen die door een gerechtsofficier op "nachtgane" betrapt waren. Dit was het zich ongeoorloofd op straat bevinden na het luiden van de avondklok. Wanneer de officier zo iemand arresteerde (het handelt hier om een administratieve aanhouding) en in de gevangenis afleverde, dan had de cipier recht op $8 \mathrm{~s}$. par. Normaliter moest de aangehoudene de volgende dag voor de rechtbank verschijnen. Bleef hij evenwel toch langer dan die ene nacht in de gevangenis, dan was ook het gebruikelijke boeigeld voorzien. Indien de gevangene op de terechtzitting evenwel werd vrijgesproken, kreeg de cipier helemaal niets (artikel 8).

$$
* *
$$

Maar waaruit bestonden nu die teerkosten ? Twee artikels brengen klaarheid in de zaak (artikel 12 en 13). Zoals reeds aangehaald vertoont de omschrijving van teerkosten heel wat gelijkenissen met de verordening van 1401 . Liet de gevangene zijn onderhoud aan de cipier over, dan mocht laatstgenoemde niet meer aanrekenen dan 6 s. par per dag (hetzelfde bedrag dat in 1401 voorzien was). Daarvoor 
moest de cipier hem twee maaltijden per dag verschaffen, en elke maaltijd moest bestaan uit soep, tarwebrood, wat bier, boter, andere toespijzen, vlees of vis.

Toch werd bepaald dat elke gevangene eventueel zelf voor zijn teerkosten kon instaan. In dat geval was de cipier verplicht om zonder bijkomend loon of salaris, op de Markt te halen of te laten halen "houdt, broot, spijse ende dranc". Over deze tweede mogelijkheid werd in de geciteerde verordening met geen woord gerept.

Het negende artikel bevat enkele bepalingen aangaande overtreders van de spertijd. Zo is uitdrukkelijk vastgelegd dat de baljuw personen die de spertijd overtraden (en zich schuldig gemaakt hadden aan nachtgane), nog de dag volgend op hun aanhouding voor de rechtbank moest brengen. De achterliggende grond was ongetwijfeld dat de cipier voor het bewaren van die personen enkel een eenmalige som van $8 \mathrm{~s}$. par. opstreek, en hij bij vrijspraak zelfs geen vergoeding kreeg. Vanuit het oogpunt van de cipier was het dan ook financieel veiliger dat deze gevangenen een zo kort mogelijke tijd in de cel doorbrachten.

Een ander artikel regelt het gebruik van de gevangenis door andere ambtenaren (artikel 10). Voor gevangenen die niet door vorstelijke of stedelijke gerechtsdienaars afgeleverd werden, maar wel door gerechtsofficieren van plattelandsschepenbanken of leenhoven moest de burggraaf zijn gevangenis niet ter beschikking stellen. Deed hij dit toch, dan waren de ambtenaren van die schepenbanken of leenhoven ertoe gehouden alle kosten te dragen.

Aan het afleveren, afhalen en terugbrengen van gevangenen zijn twee artikels gewijd. Artikel 11 stipuleert dat alle officieren de gevangenen aan de poort moesten afleveren. De cipier kon dus nooit gevraagd worden om ergens een gevangene op te halen. Uit artikel 14 blijkt dat wanneer een gevangene voor de rechtbank of een gerechtsofficier diende te verschijnen (b.v. voor een ondervraging) het transport daarheen niet door de cipier gebeurde. Het belangrijkste element was evenwel dat diegene die de gevangene afhaalde verplicht was deze achteraf opnieuw bij de cipier in te leveren, opdat de cipier steeds de mogelijkheid zou hebben zijn onkosten op de gevangene te verhalen. Bleef de gerechtsofficier hiervan in gebreke, dan draaide hij zelf voor die kosten op. Het reglement zegt wel dat, wanneer men een gevangene afhaalde, de cipier ertoe gehouden was de officier op deze verplichting te wijzen, alsook diende hij melding te maken hoeveel de kosten bedroegen. Ook Wielant ziet de 
moeilijkheden die dit alles met zich mee kan brengen, vooral wanneer de gevangene door de rechtbank werd vrijgesproken : "Den cipier moet de ghevanghenen gheabsolveert van crime stappans ontslaen ende laeten gaen behouden hem zijne actie van zijne costen up den ghuenen die hem ghelevert heeft of ghedaen leveren ende dit naer rechte. Maer naer usancie ende costume den cipier behoudt ziin ghevanghene tot dat hy betaelt es van den steen of vanghenes costen" (Pr. cri., XVII, p. 26).

Het slotartikel beoogt misbruiken tegen te gaan. Daartoe waren te Ieper twee voogden aangsteld (artikel 15). Volgens dit reglement werd er één benoemd door de stadsschepenen, de andere door de burggraaf. De ontwerpcostumen van 1535 (titel IL, artikel 2) stellen evenwel dat twee schepenen (aangeduid bij de vernieuwing van de schepenbank) voor de controle van de gevangenis moesten instaan. In elk geval moesten zij minstens één keer per week de gevangenis inspecteren en hiervan verslag uitbrengen bij de schepenbank. Hun taak was in feite meervoudig. Vooreerst overbezetting van de gevangenis vermijden, door erop toe te zien dat de aalmoezen die behoeftige gevangenen gratis ontvingen, in de juiste handen terechtkwamen. Anderzijds moesten beide voogden ervoor zorgen dat de cipier zijn boekje niet te buiten ging, alsook aan de gevangenen vragen of ze voor het gerecht wilden verschijnen. De ontwerpcostumen (titel IL, artikel 3) stipuleerden daarenboven dat de cipier riskeerde voor het gerecht gedaagd te worden indien hij de inspecteurs bij hun werkzaamheden hinderde. Merk ten slotte nog op dat het plakkaat van 9 juli 1570 over de gevangenissen bepaalde dat de gevangenissen minstens één keer per maand door de vorstelijke vertegenwoordiger (de baljuw) of zijn plaatsvervanger dienden gecontroleerd te worden, en dit in het bijzijn van twee rechters en een griffier $^{12}$. Daarbij moest men de gevangenen ondervragen over gegevens die het proces konden laten opschieten. Daarenboven diende men na te gaan of de gevangenen voldoende voedsel ontvingen, en of de verblijfsomstandigheden in orde waren. Of dit in Ieper ertoe geleid heeft dat de controle door de voogden verviel, dient verder onderzoek uit te wijzen.

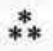

12. Vyfden Placcaert Boeck van Vlaenderen, dl. I, 2de boek, rubrica V, artikel 39, Gent, 1763, p. 185 . 
Uit de korte ontleding moge blijken dat een economisch motief aan de basis lag van dit reglement. Bedoeling was de inkomsten en uitgaven van de Ieperse cipier, alsook diens rechten en plichten met een eventuele financiële weerslag (b.v. het afhalen van gevangenen, het ontvangen van gevangenen van lokale schepenbanken en leenhoven...) duidelijk vast te leggen. Aangezien de tekst gehecht is aan een verzoek van de gevangenisbezitter tegenover de baljuw met het oog op het nakomen van de financiële plichten door laatstgenoemde, kan men afleiden dat er moeilijkheden bestonden aangaande dit punt.

De financiële rechten en plichten van de Ieperse cipier hebben doorheen de $15 \mathrm{de}$ eeuw weinig veranderingen ondergaan. Het reglement bevat in wezen nog dezelfde bepalingen als de ordonnantie van 1401 .

Tenslotte valt op dat men zelfs in een beknopt gevangenisreglement heel wat rechtshistorische elementen terugvindt, zowel aangaande de criminele als de burgerlijke procedure. 


\section{BIJLAGE}

Ordonnancie van der vanghenesse ende van den rechte van de cepier BRUSSEL, ALGEMEEN RIJKSARCHIEF, Cartons Rekenkamer, 1ste reeks, 228.

I. Eerst van elken persoon die partielic ghearresteert es ende in vanghenesse ghebrocht wert omme schulden zal de cepier ontfaen van uut ende ingane achtentwintich grooten ende bovendien van yserghelde eenen braspenninc elcx daechs, metgaders teerlicke costen indien hij die van den cepier ghehadt heift.

IJ. Item die bij den heere in vanghenesse ghelevert zijn omme pennincboeten ghewijst ofte ghecomposeert, zal de cepier hebben ende ontfaen ghelijc als vooren.

IIJ. Item van persoonen die omme civile boete ende onghewijst ghevanghen werden ende daernaer bij vonnesse van der wet costeloos quijte ghewijst ende ontsleghen zijn ofte bij den heere als ombesculdich ende gheen recht daerin hebbende ghedelivreert en zal de cepier niet hebben dan de vertherde costen zonder meer.

IIIJ. Item van ghevanghenen bij den heere omme delict of mesus ten verzoucke van partien of daer partie clachtich es metten heere heesschende reparacie ende beteringhe, de cepier sal ontfaen vul recht ghelijc van der ghevanghenen van sculden.

V. Item ende van ghevanghenen bij den heere of bij der wet ter cause van crime ende dat hij bij composicie of submissie met civile beteringhe ghestaet van dien wert insghelijcx de voornoemden cepier gherecht als vooren van sculden.

VJ. Item van persoonen die bij den wet gheordonneert werden ende bevolen in vanghenesse te gane in vormen van pugnicien omme huerlieden mesus te wat cause dat zij, zal de cepier ontfaen yzerghelt te wetene eenen braspenninc sdaechs ende vertheerde costen.

VIJ. Item van persoonen die bij indaghinghen jeghens den heere of partie commen in vanghenesse ofte bij purge, sal de cepier ontfaen yserghelt ende de montcosten zonder meer.

VIIJ. Item van persoonen die in vanghenesse gheleit werden bij den heere voor de boete van nachtgane, zal de cepier ontfaen voor de eerste nacht achte grooten voor al, ende indien zij daer langher vernachten zal boven de voornoemde achte grooten men van hemlieden ontfaen yserghelt te wetene voor elcken dach eenen braspenninc, ende indien zij quijte ghewijst worden van der voornoemde boette werden onghehouden van al den voornoemden rechten te betalene.

IX. Item wert ooc de bailliu alzulcke ghevanghenen van nachtgane 
ghehouden tsanderdaechs van dat zij ghevangen werden, te bringhene ter cameren voor mijn heeren van der wet om te rechte te stane zonder langher te verbeydene noch delayerene.

$X$. Item nopende den ghevanghenen persoonen die in der vanghenesse ghebrocht werden bij den officiers van den vassael heeren of andere smalle heeren, den welken officiers mijn heere den burchgrave mainteneert onghehouden te zijne vanghenesse te leverne ende huere ghevanghenen niet te moeten ontfane, de voornoemde mijn heere den burchgrave blijft daerof ghehouden gheheel dien ghevanghenen te doen ontfane bij zinen cepier zulc recht ende sallaris als hij zeight hem toebehoorende zonder bij desen hem eenichsins te preiudicierene ofte te verminderene.

XJ. Item werden de baillius, scoutheetene ende officiers alle huere ghevanghenen die zij in vanghenesse bringhen ten verzoucke van den heere ofte van partien, tzij van crime ofte van civile zaken, ghehouden te bringhene ende leverne boven binder duere ende pourprijse van der voornoemde vanghenesse, ende anders en wert de cipier ghehouden last daerof te nemene noch te bewaerene.

XIJ. Item niement en wart ghehouden te nemene of hem te stellene in de costen van den cepier dan die wille, maer mach elc ghevanghenen zijn propren costen doen. Ende wert de cepier zonder loon of sallaris daerof te hebbene ghehouden te halene of te doen halene binnen den vierhoucken van der marct of daerontrent binnen der langhde van diere om zijn ghelt, houdt, broot, spijse ende dranc als hem redelic behouft.

XIIJ. Item ende indien yement theercosten hebben wille van den cepier, zo zal de zelve cepier daervooren niet meer moghen rekenen noch ontfaen dan voer elken dach zes grooten, te wetene twee maeltijden sdaechs ende voor elke maeltijt goede pottaige, tarwebroode, een vierendeel groot biers, buetere ende andere toespijse, vleesch of visch, naer dat den dach ghetijdich wart.

XIIIJ. Item alle ghevanghenen die dofficiers ende ballius van der stede uuter vanghenesse haelen zullen ende die bringhen voor de wet omme te rechte te stane ofte andersins ghehoirt te zijne, werden de zelve officiers ende baillius ghehouden die ghevanghenen wederomme te leverne in de voorseide vanghenesse omme den cepier van zijnen rechte ghecontenteert te zijne, up indien zij daerof in ghebreke bevonden waren zelve den voornoemden cepier van zijnen rechte te vuldoene ende betalene, wel verstaende dat den cepier ten halene van den ghevanghenen ghehouden wert den vorseiden officiers ende baillius tadverterene ende hemlieden te zegghene dat zij 
hem de voornoemden ghevanghenen weder leveren in vanghenesse, insghelijcx ooc van zoevele zij ghevanghenen themwaerdere ghehouden zijn ter cause van zijn rechte van cypaege.

$X V$. Item ten fine dat de vanghenesse voortan niet verlast en worde van ghevanghenen, dat ooc daelmoesenen van den zelven ghevanghenen bet ende behoorlijcker ghedistribueert zij den ghonen dient behooren ende anders niement, zijn gheordonneert twee notable persoonen als vooghden ende bezorghers van den ghevanghenen. Van den welken twee mannen mijn heere van der wet den eenen stellen zullen ende burchgrave den anderen. Die thuerlieden discretie emmere elke weke ten minsten visenteren zullen de voornoemde vanghenesse ende weten of daer yemende van den ghevanghenen beheert, ghehoort ende te rechte ghestelt te zijne. Zullen ooc regart nemen of de ghevanghenen behoorlick ghetracteert zijn ende de aelmoesenen ghedestribueert dient behoort. Van al den welken zij rapport doen zullen mijn heeren van der wet omme up al voorzien tzijne zoot behooren zal.

\section{Woordenlijst $^{13}$}

besorger $=$ opzichter, inspecteur

bueter $=$ boter

cipaege $=$ gevangenisrecht

delivreren $=$ bevrijden

getijdich $=$ op het juiste ogenblik

groot = zilvermunt ter waarde van $1 \mathrm{~s}$. par. ; in artikel 13 ("een vierendeel groot biers") is waarschijnlijk bier tot een waarde van $1 / 4 \mathrm{~s}$. bedoeld indaginghe $=$ daging, dagvaarding nachtgane $=$ 's nachts ongeoorloofd op straat lopen ongewijst $=$ vooraleer er een vonnis geveld is, ongevonnist partielic $=$ op verzoek van een partij pourprijse $=$ afgesloten ruimte, omheining, plaats door muren omgeven prejudicieren $=$ nadeel of schade berokkeneen

purge $=$ zuiveringsprocedure ten bewijze van onschuld smalheer $=$ heer van een klein leen submissie $=$ scheidsrechterlijke uitspraak verbeyden $=$ talmen, afwachten

13. De woordenlijst werd opgesteld aan de hand van K. STALLAERT, F. DEBRABANDERE, Glossarium van verouderde rechtstermen..., 3 dln., Leiden-Handzame, 1890-1977 ; J. VERDAM, Middelnederlandsch handwoordenboek, Den Haag, 1964 ; M. VAN HATTUM, H. ROOSEBOOM, Glossarium van oude Nederlandse rechtstermen, (Verzamelen en bewerken van de jurisprudentie van de Grote Raad, nieuwe reeks, nr.2), Amsterdam, 1977. 
verlast $=$ overbelast

vernachten $=$ overnachten, verblijven

vierhoucken $=$ vierkant, oppervlakte

ysergheld $=$ boeigeld, vergoeding die de cipier kreeg om de gevangenen deftig onderdak te verschaffen 